\title{
Use does not wear ragged the fabric of friendship: Thinking of objects as alive makes people less willing to replace them
}

\author{
Jesse Chandler*, Norbert Schwarz \\ University of Michigan, USA
}

Received 10 August 2008; accepted 20 December 2009

Available online 27 January 2010

\begin{abstract}
Anthropomorphic beliefs about objects lead people to treat them as if they were alive. Two experiments test how anthropomorphic thought affects consumers' product replacement intentions. Consumers induced to think about their car in anthropomorphic terms (i) were less willing to replace it and (ii) gave less weight to its quality when making replacement decisions. Instead, they (iii) attended to (experimentally induced connotations of) the car's "warmth," a feature usually considered relevant in the interpersonal domain. While anthropomorphic beliefs about brands are often seen as advantageous by marketers because they increase brand loyalty, similar beliefs about products may be less desirable. (C) 2009 Society for Consumer Psychology. Published by Elsevier Inc. All rights reserved.
\end{abstract}

Although most people know that cars and computers are inanimate, at times they treat them as if they were alive. Most of us at some point have argued (or pled) with a computer, felt attached to a favorite sweater or expressed love for a new car. Anthropomorphic objects are also commonly featured in movies and books intended for both children (e.g., The Brave Little Toaster, Disch, 1987) and adults (e.g., 2001: A Space Odyssey, Kubrick, 1968). People are experts in representing, predicting and interacting with both the physical and social worlds. When thinking about objects and people, there are important differences in the processing of information, both at a neural level (Mitchell, Heatherton \& Macrae, 2002; Yoon, Gutchess, Feinberg \& Polk, 2006) and in terms of self-report and behavioral measures (e.g. Cosmides, 1989). Thus, whether a target is categorized as living or not has downstream consequences on what information comes to mind, what information is deemed relevant and what predictions seem plausible when thinking about the target.

We examine the consequences of anthropomorphism on the kinds of information consumers' attend to when forming product replacement intentions. Whereas objects are primarily evaluated based on how well they function, functionality is far

\footnotetext{
* Corresponding author. Department of Psychology, University of Michigan, 530 Church Street, Ann Arbor, MI 48109-1043, USA.

E-mail address: jjchandl@umich.edu (J. Chandler).
}

less important when evaluating people — and we assume that the same may hold for anthropomorphized objects. We predict, and find, that priming anthropomorphic beliefs about a product shifts attention away from pragmatic considerations (such as the product's functionality) and makes consumers sensitive to information that figures prominently in the interpersonal realm (such as the product's perception as "warm" or "cold"). Specifically, consumers (i) reported lower intentions to replace their car when they were induced to think about it in anthropomorphic terms. More importantly, (ii) thinking about one's car in anthropomorphic terms decoupled replacement intentions from the car's perceived quality and functionality (Studies 1 and 2). Instead, (iii) consumers who were primed to think about their car in anthropomorphic terms turned to information that is valued in the interpersonal domain and were less likely to replace their car when its color was associated with (experimentally manipulated) "warm" rather than "cold" connotations (Study 2). Next, we review relevant research and develop our rationale in more detail.

\section{Anthropomorphic thought}

In principle, almost any object of thought can become anthropomorphized, even invisible entities (e.g. ghosts; Bering, 2006) or purely symbolic concepts (e.g. brands; Aaker, 1997; for a review see Guthrie, 1993). People are particularly likely to 
spontaneously anthropomorphize objects that have human-like physical features, such as eyes (Haley \& Fessler, 2005; Jipson \& Gelman, 2007), hands (Woodward, 1999) or a human-like form (Aggarwal \& McGill, 2007), or that behave in an apparently complex or intentional manner (Heider \& Simmel 1944; Epley, Waytz, Akalis \& Cacioppo, 2008). In addition, individual difference variables, like loneliness and desire for social contact, are associated with a higher propensity to anthropomorphize objects (Epley, Akalis, Waytz, \& Cacioppo, 2008). Throughout, the findings are compatible with general models of knowledge accessibility (Higgins, 1996) and suggest that any variable that increases the temporary or chronic accessibility of agentic beliefs is likely to foster anthropomorphic thought about objects (for a review of the causes of anthropomorphic beliefs see Epley, Waytz \& Cacioppo, 2007).

Once a product is anthropomorphized, it becomes possible for consumers to enter into a relationship with it, changing the emotional quality of consumers' experience with their possessions. Social interaction is pleasurable, and imbuing a product with anthropomorphic cues leads consumers to experience more positive affect when interacting with it (Wang, Baker, Wagner \& Wakefield, 2007). Indeed, even in the absence of anthropomorphic cues, some consumers spontaneously experience uniquely social emotions when interacting with objects, including love (Schultz, Kleine \& Kerman, 1989) and trust (Aaker, Fournier \& Brasel 2004). Over time, connections to special products and objects can grow, leading consumers to form a sense of attachment that parallels interpersonal attachment patterns (Wallendorf \& Arnould, 1988; Ball \& Tasaki, 1992; Bowlby, 1980). As a result, much like in interpersonal relationships, consumers can come to depend on objects, feeling a sense of security when they are close and distress when they are absent (Thomson, MacInnis \& Park, 2005). Some companies have experimented with capitalizing on customers' feelings of loyalty to reduce business costs. For example, Zipcar decided to name all of its rental vehicles and reported that this led customers to be more diligent about cleaning and maintaining them (Levine, 2009). In combination, these observations suggest that consumers should be less willing to replace a product they own when they think about it in anthropomorphic terms.

In addition, anthropomorphizing a product should reduce the usually observed link between perceived product quality and replacement intentions. This prediction follows from the observation that thought about the inanimate world is usually dominated by instrumental considerations, whereas thought about the social word is not. For example, perceived product quality and performance are central to product evaluation and these instrumental attributes usually trump more symbolic attributes, such as brand image and brand personality (Zentes, Morschett \& Schramm-Klein, 2008). In a study of retail store brands, Zentes and colleagues found that the effect of store performance on attitudinal and behavioral measures of customer loyalty far exceeded the effect of customers' perceptions of brand personality. In contrast, people maintain interpersonal bonds with relatively little regard for the instrumental contributions offered by others (Leach, Ellemers, \& Barreto,
2007; Jones \& Vaughan, 1990). Instead, considerations of the intentions behind actions (Falk, Fehr \& Fischbacher, 2008), communality and relational status often trump considerations of instrumentality, like the actual contributions of the other's skills and competence to one's own outcomes (Wojciszke, Bazinska \& Jaworski, 1998; for a recent review see Ybarra et al. 2008). In a relational context, social features of identity are particularly salient and people are more likely than not to behave in a manner consistent with accessible features of identity (Oyserman, 2009). As a result, social relationships are maintained even when they require costly sacrifices (Simmons, Marine \& Simmons, 1977) and people routinely invest resources in caring for the old, the sick and the weak, even when they can no longer serve a useful function (Branscombe, Wann, Noel, \& Coleman, 1993; Levine \& Moreland, 2002). By changing the perceptions of a product, anthropomorphic cues may also make relational aspects of the self salient, allowing the product to fulfill identity based motives (e.g., Aaker \& Akutsu, 2009; Shavitt, Torelli \& Wong, 2009).

When people think about objects in anthropomorphic terms, they apply knowledge about the social world to the inanimate world. This is reflected in categorization decisions (e.g., Jones, Smith \& Landau, 1991) and the use of social categories (like gender or age) in the description of objects (e.g., Heider \& Simmel, 1944; Berry \& Springer, 1993). Moreover, people apply social schemas to objects and prefer objects that fit the schema. This leads consumers to prefer product lines that match social structures, such as "family," and cars that smile rather than frown (Aggarwal \& McGill, 2007). Thus, "ownership" may instead become a "relationship" and the features relevant to relational partners may become applicable to anthropomorphized objects.

In combination, these considerations lead to the following three predictions. When consumers think about a product in anthropomorphic terms they are (i) less willing to replace it; (ii) less likely to base replacement decisions on instrumental attributes of the product, thus decoupling perceived product quality and replacement intentions; and (iii) more likely to consider attributes that are usually deemed important in the interpersonal domain.

\section{The present research}

We test these predictions in two studies, using an experimental strategy that differs from the two dominant strategies employed in anthropomorphism research. One common strategy is essentially correlational and relies on observed parallels between social cognition and object cognition as evidence of anthropomorphic thought (e.g., Aggarwal, 2004; Berry \& Springer, 1993; Heider \& Simmel, 1944; Schultz et al., 1989; Thomson, MacInnis \& Park, 2005; Wallendorf \& Arnould, 1988; Ball \& Tasaki, 1992). A second common strategy endows objects with human features to elicit anthropomorphic beliefs, e.g., by having the object talk, smile, frown, and so on (e.g., Aggarwal \& McGill, 2007; Epley et al., 2008; Jones et al., 1991). Although both approaches have demonstrated anthropomorphic thoughts about objects, skeptics 
may wonder to which extent the results reflect the spontaneous application of social knowledge to objects as opposed to the influence of pragmatic linguistic or situational considerations. From this perspective, parallels between how individuals describe objects and people may reflect mere linguistic convenience. Moreover, the presentation of novel objects with human features may convey that the object is to be thought about in human terms - or why else would it be endowed with these features? Hence, the observation of apparent agentic beliefs about an anthropomorphized object may, at least in part, be the result of pragmatic inferences about the intentions of the communicator (Schwarz, 1996).

The present studies address these ambiguities in two ways. First, our dependent variable does not consist of object descriptions that may invite the use "human" terms for reasons of linguistic convenience. Instead, we assess product replacement intentions as a decision to which social norms are applicable. Second, we hold the object constant and manipulate, through a preceding question, whether technical or "psychological" attributes of the object are likely to come to mind. Following this manipulation, participants describe the product in their own words and report how likely they are to replace it in the near future.

\section{Study one}

\section{Method}

Participants $(N=92)$ completed the study online for partial course credit. They were randomly assigned to one of three conditions (Anthropomorphism, Object, and Control) and told that the survey explored "what people think about their cars." Participants assigned to the Anthropomorphism condition first rated their car on five bipolar scales anchored with personality traits (reserved - enthusiastic, quarrelsome - sympathetic, dependable - irresponsible, open to new experiences - uncreative, and anxious - calm), whereas participants assigned to the Object condition rated mechanical attributes of their car (quiet - loud, unresponsive - responsive, unreliable - reliable, versatile - limited, shaky - smooth). Pilot testing revealed that in a free association task, people spontaneously listed more agentic nouns (people or other living entities) following presentation of the Anthropomorphism adjectives than the Object adjectives, $F(1,18)=45.33, p<.001$, confirming that the personality adjectives are more likely to bring anthropomorphic concepts to mind. Participants assigned to the Control condition completed neither of these scales. Subsequently, participants described their car in their own words and rated the likelihood that they would replace their car before they left college $(1=$ not at all, 7 = very much so).

\section{Results}

\section{Manipulation check}

Participants' descriptions of their cars were coded for the presence of anthropomorphic language by two independent coders. Anthropomorphic language included mentioning that their vehicle had a name, use of animate pronouns (he/she), elaboration of the vehicle's "personality" using agentic trait descriptions beyond those provided in the rating scales, and the use of interpersonal emotions (e.g. "love") when describing their attitude toward their car (Schultz et al., 1989). Agreement between coders about the presence of anthropomorphic language was high, $\kappa=.88$. A chi-square analysis revealed that participants were more likely to describe their car in anthropomorphic language in the Anthropomorphism condition $(48 \%)$ than in the Object $(29 \%)$ or Control condition $(15 \%)$, $\chi^{2}(2,90)=8.41, p<.02$. This confirms that our manipulation worked as intended. ${ }^{1}$

Participants' open ended descriptions of their cars were also coded for valence by two coders blind to conditions and hypotheses $(\alpha=.86)$; the coders' ratings were averaged to create a composite measure of perceived car quality $(-3=$ extremely negative description; $+3=$ extremely positive description). Planned contrasts were computed to compare the anthropomorphism condition to the other two conditions and both ratings scale conditions to the no-rating control condition; neither of these contrasts showed a difference in overall valence of participants' descriptions of their car, $F \mathbf{S}<1$.

\section{Hypotheses tests}

Next we turn to participants' willingness to replace their car. A planned contrast (Rosenthal, Rosnow \& Rubin, 2000) comparing the anthropomorphic condition to the other two conditions confirmed that participants reported less intention to replace their car after rating its personality characteristics (Anthropomorphism condition, $M=2.23, S D=1.54$ ) than after rating its technical characteristics (Object condition, $M=3.14$, $S D=2.24$ ) or providing no attribute rating (Control condition, $M=3.15, S D=2.04), F(1,89)=4.52, p<.04, \eta_{\mathrm{p}}{ }^{2}=.05$. Followup contrasts revealed that the anthropomorphic condition differed from the object condition, $F(1,89)=3.21, p<.05$, one-tailed, as well as the control condition, $F(1,89)=3.55$, $p<.05$, one-tailed, whereas the latter two conditions did not, $F<1.2$.

To test whether this pattern implies the predicted dissociation between perceived product quality and replacement intentions, we analyzed the relationship between the valence of participants' open ended car descriptions and their replacement intentions in the anthropomorphic and non-anthropomorphic conditions using regression. Replacement intentions were regressed on a contrast code comparing the anthropomorphic condition to the object and control conditions (for a discussion of planned contrasts in regression analyses, see Cohen, Cohen, West \& Aiken, 2003). Overall, participants reported higher intentions to replace their car the more negatively they had described it, $\beta=-.50 t(87)=4.17, p<.001$, as one would expect. In addition, they reported lower intentions to replace their car when they had thought about it in personality terms, $\beta=-.21$, $t(87)=2.21, p<.03$, reflecting the findings discussed above. More important, however, these main effects were qualified by

\footnotetext{
${ }^{1}$ For both manipulation checks, we report the results of the coder who reported the smallest difference between conditions.
} 
an interaction between anthropomorphic prime and car quality, $\beta=.25, t(87)=2.10, p<.05$, shown in Fig. 1 . An examination of the simple effects revealed that while poor quality reports were associated with increased intention to replace in the Object and Control conditions, $\beta=-.45, t(58)=3.56, p<.001$, intention to replace was unrelated to quality in the Anthropomorphic condition $\beta=-.12, t(28)<1$.

This pattern is also reflected in the correlations between quality descriptions and replacement intentions. The more positively participants described their car, the less willing they were to replace it in the Object condition, $r(22)=-.50, p<.02$, followed by the Control condition, $r(26)=-.32, p<.10$. In contrast, the relationship between these variables was small and not significant in the Anthropomorphism condition, $r(24)=$ $-.15, p>.4$, as observed in the regression.

\section{Discussion}

In sum, participants described their cars using more anthropomorphic and interpersonal language when a preceding question asked them to rate their car on personality traits rather than technical characteristics, confirming the successful induction of anthropomorphic thoughts. While the anthropomorphism manipulation did not affect the valence of participants' open ended descriptions of their cars, it did affect their replacement intentions. As predicted, participants (i) reported lower replacement intentions when they were induced to think about their car in anthropomorphic terms. Moreover, (ii) perceived product quality, as coded based on the valence of participants' open ended descriptions, predicted replacement intentions in the absence of anthropomorphic primes, but was unrelated to replacement intention when anthropomorphic beliefs were primed. These findings provide first evidence that anthropomorphism can decouple product quality and

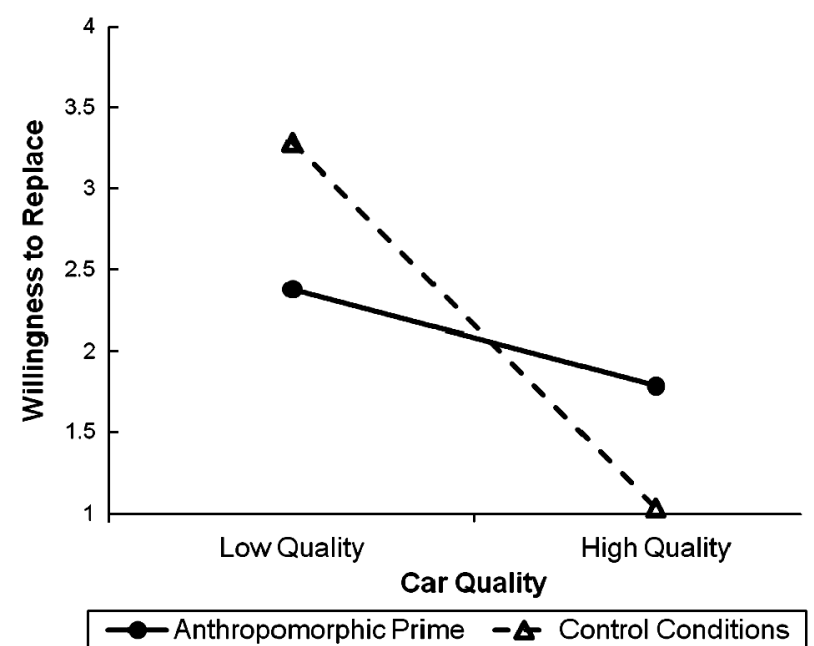

Fig. 1. The relationship between description valence and people's willingness to replace it before they leave college. Participants in the Anthropomorphism condition filled out a personality questionnaire for their car. Control conditions either rated their car on non-anthropomorphic traits or did not rate their car. Description valence was evaluated by coding participants' descriptions of their cars. Low and high values are plotted one standard deviation below and above the mean (Study 1). replacement intentions, consistent with the conjecture that consumers may hesitate to replace anthropomorphized possessions just because they get unreliable, much as they hesitate to replace close friends just because they get old and cranky.

Nevertheless, two methodological concerns deserve attention; both pertain to unintended effects of our anthropomorphic thought manipulation. First, the personality traits we used as anthropomorphic primes may also have primed other positive features of the product. These features may be unrelated to anthropomorphic thought per se, but may result in more positive evaluations and hence lower replacement intentions. Second, rating the car on technical characteristics vs. personality characteristics may not only have primed technical vs. anthropomorphic concepts (as was intended), but the rated attributes themselves may have differential evaluative implications. Both of these concerns imply that differences in anthropomorphic thought may be confounded with a differential accessibility of valenced attributes of the car. Empirically, the data provide no support for this conjecture. Any difference in the accessibility of valenced attributes should be reflected in participants' subsequent free-response descriptions of their cars; yet these descriptions showed no difference in valence $(F<1)$.

\section{Study two}

Study 1 showed that consumers base their replacement intentions on the perceived quality of the product in the absence of anthropomorphic thought, but do not attend to product quality once the product is anthropomorphized. This observation is consistent with the assumption that instrumental considerations loom larger in the impersonal than in the personal world. By the same token, however, features that are valued in the interpersonal domain should be more likely to affect product replacement intentions when consumers are induced to think about the product in anthropomorphic terms than when they are not. Study 2 tests this prediction by manipulating participants' perception of whether their car's color is "warm" or "cold," a dimension that figures prominently in perceptions of socio-moral traits and global evaluations of positivity in interpersonal contexts (Asch, 1946; Ijzerman \& Semin, 2009; Williams \& Bargh, 2008).

\section{Method}

Participants $(N=127)$ completed the study online for partial course credit; they were randomly assigned to the conditions of a 2 (Color Labels: warm vs. cold) $\times 3$ (Primes: anthropomorphism, object and a no prime control)-factorial betweenparticipants design.

To manipulate the warm or cold connotations of the car, participants were asked to select the color that most closely resembled their own car's color from a matrix of nine colored squares. The five most common car colors (accounting for $90 \%$ of all new car sales; Dupont, 2006) were labeled with "warm" (e.g., "summer blue") or "cold" (e.g., "blizzard blue") names. All participants saw a mixture of "warm" and "cold" color names along with four foil colors (e.g., "canary yellow") and 
had to remember the name of their own car's color as part of an alleged memory task. Note that this procedure ensured that all participants were exposed to a mix of warm and cold color names, thus avoiding the problem that some participants would only be exposed to warm and others only to cold concepts; instead, the conditions merely differ in whether the color of the participant's own car is associated with a warm or cold label. This procedure randomly assigned 58 participants to the Warm and 64 participants to the Cold condition; 5 participants who forgot the color name associated with their car were dropped from analysis. ${ }^{2}$

Next, participants were randomly assigned to one of the thought manipulations used in Study 1. Subsequently, they described their car in their own words, indicated their desire to replace their car before they left college $(1=$ not at all; $7=$ very much), and reported the name assigned to the color of their car (thus completing the memory task).

Results

\section{Manipulation check}

Participants' descriptions of their cars were again coded for the presence of anthropomorphic language by two independent coders. Agreement between coders about the presence of anthropomorphic language was high, $\kappa=.86$. A chi-square analysis revealed that participants in the anthropomorphism condition were more likely describe their car in anthropomorphic language (24\%) than participants in either the object $(7 \%)$ or the control condition $(6 \%), \chi^{2}(2,162)=10.82, p<.01$. This confirms that the manipulation worked as intended.

Participants' open ended descriptions of their cars were coded for valence by two coders blind to conditions and hypotheses $(\alpha=.89)$; the coders' ratings were averaged to create a composite measure of perceived product quality $(-3=$ extremely negative description; $+3=$ extremely positive description). Analyses of this index of perceived product quality revealed no influence of the experimental manipulations (all $p \mathrm{~s}>.3$ ).

\section{Hypotheses tests}

Replicating Study 1, a planned contrast (Rosenthal et al., 2000) comparing the Anthropomorphism condition to the other two conditions confirmed that participants reported less intention to replace their car after rating its personality characteristics (Anthropomorphism condition, $M=2.83$, $S D=1.54$ ) than after rating its technical characteristics (Object condition, $M=3.84, S D=2.24$ ) or providing no attribute rating (Control condition, $M=3.82, S D=2.04), F(1,118)=6.15$, $p<.05, \eta_{\mathrm{p}}^{2}=.05$. Follow-up contrasts revealed that the Anthropomorphism condition differed from the Object condition, $F(1,118)=5.08, p<.05$, as well as the Control condition, $F(1,118)=4.15, p<.05$, whereas the latter two conditions did not differ from one another, $F<1$.

\footnotetext{
${ }^{2}$ In addition, 31 respondents reported car colors outside the range of the 5 most common ones. Because the experimental manipulation of the color connotations only covered the common colors, these respondents could not be assigned to one of the experimental conditions.
}

Next we turn to the influence of description valence and temperature prime. Replacement intentions were regressed on description valence, the warm/cold manipulation and a contrast code comparing the Anthropomorphism condition with the Object and Control conditions. Overall, participants who described their car negatively were more willing to replace it, $\beta=-.47, t(115)=4.84, p<.001$. Moreover, participants assigned to the Anthropomorphism condition reported lower replacement intentions than participant assigned to the Object or Control conditions, as reflected in a main effect of the dummy variable representing the anthropomorphism condition, $\beta=-.22, t(115)=2.65, p<.01$. However, these main effects were qualified by two interactions. Replicating Study 1, an interaction between the Anthropomorphism condition and perceived product quality again indicates that anthropomorphic thought dissociates replacement intentions from perceived product quality, as shown in Fig. $2, \beta=.22, t(115)=2.34$, $p<.03$. As in Study 1, participants in the Control, $r(34)=-.59$, $p<.001$, and Object condition, $r(45)=.41, p<.001$, reported higher replacement intentions the more negatively they described their cars, whereas the two variables were unrelated in the Anthropomorphism condition, $r(40)=-.07, n s$.

Going beyond the replication of Study 1, an interaction of the two experimental manipulations was also observed, $\beta=-.21$, $t(115)=2.12, p<.04$ (Fig. 3). An examination of simple slopes revealed that, as predicted, participants were particularly unwilling to replace anthropomorphized cars when their color had been associated with a warm $(M=2.23, \mathrm{SD}=1.77)$ rather than cold $(M=3.48, \mathrm{SD}=2.10)$ color label, $t(115)=1.90, p<.05$, one-tailed, for the simple effect. In contrast, color labels did not influence participants' replacement willingness in the object $\left(M_{\text {warm }}=4.00, \mathrm{SD}=2.44\right.$ and $\left.M_{\text {cold }}=3.72, \mathrm{SD}=1.86\right)$ and control conditions $\left(M_{\text {warm }}=4.17, \mathrm{SD}=2.14\right.$ and $M_{\text {cold }}=3.44$, $\mathrm{SD}=2.22), t<1$.

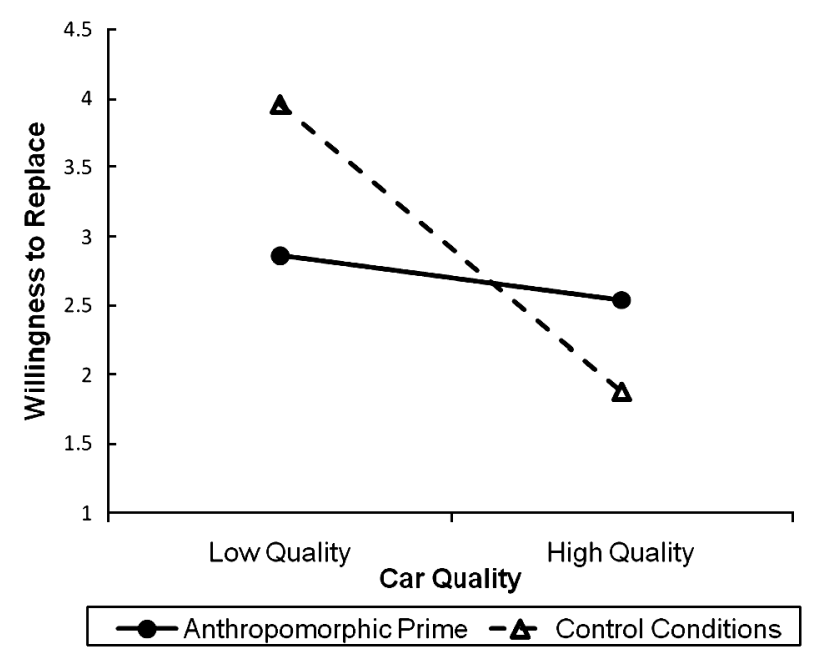

Fig. 2. The relationship between description valence and people's willingness to replace it before they leave college. Participants in the anthropomorphism condition filled out a personality questionnaire for their car. Control conditions either rated their car on non-anthropomorphic traits or did not rate their car. Description valence was evaluated by coding participants' descriptions of their cars. Low and high values are plotted one standard deviation below and above the mean (Study 2). 


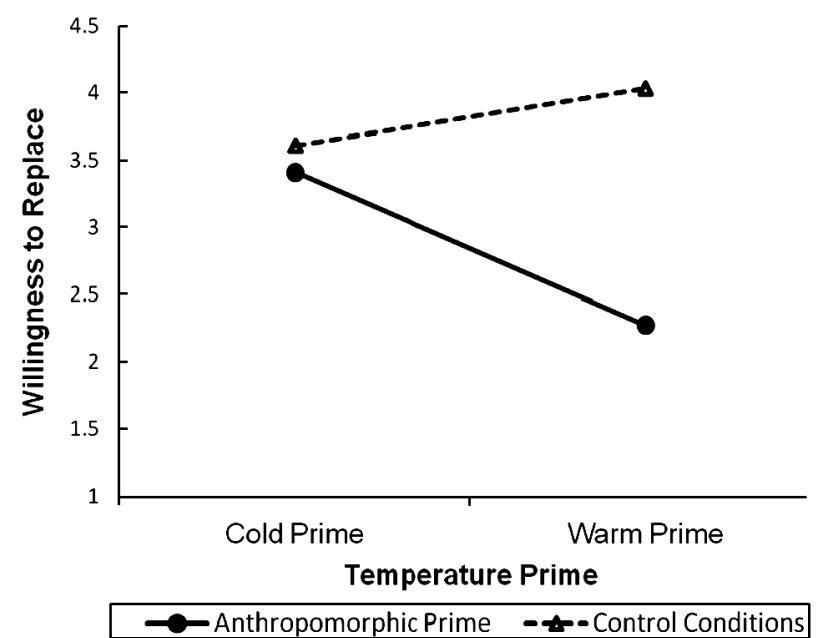

Fig. 3. The relationship between temperature prime and people's willingness to replace it before they leave college. Participants in the anthropomorphism condition filled out a personality questionnaire for their car. Control conditions either rated their car on non-anthropomorphic traits or did not rate their car. Warm and cold prime refers to the metaphorical connotations of a color label applied to the subject's car (Study 2).

\section{Discussion}

Replicating Study 1, participants (i) reported a lower willingness to replace their car when they had thought about it in anthropomorphic terms and (ii) their replacement intention was decoupled from their perception of the car's quality, as measured by the valence of participant's descriptions of their cars. Extending these findings, participants who had thought about their car in anthropomorphic terms were (iii) particularly unwilling to replace it when they were led to perceive its color as "warm," a highly valued trait in the interpersonal domain. In contrast, warm/cold connotations of the car's color did not affect the replacement intentions reported by participants in the non-anthropomorphic thought conditions.

\section{General discussion}

Taken together, these findings show that attending to "psychological" features of a product (i) leads consumers to report lower replacement intentions (Studies 1-2) and (ii) decouples replacement intentions from considerations of product quality. Specifically, consumers' replacement intentions depended on the perceived quality of the product when anthropomorphic beliefs were not primed, but were independent of perceived product quality when anthropomorphic beliefs were primed (Studies 1-2). Conversely, thinking of "psychological" features of a product (iii) leads consumers to attend to features that are valued in the interpersonal domain. Specifically, consumers who were induced to see their car's color as "warm" reported lower replacement intentions than consumers who were induced to see it as "cold," but only under anthropomorphic thought conditions (Study 2). In combination, these findings suggest that anthropomorphic thought changes the information that consumers attend to when thinking about products while generally reducing replacement intentions.
Finally, our results illustrate that anthropomorphic thoughts about a product can be easily induced without adding anthropomorphic features to the object itself.

Note that these findings cannot be explained by assuming that our manipulation of anthropomorphic thought merely increased participants' positive regard towards their cars. First, we observed no difference in the positivity of participants' freeresponse descriptions of their cars to begin with. Second, even if observed, any increase in positive regard would merely predict decreased replacement intentions. This prediction, however, falls short of accounting for two other key findings: it provides no rationale for the decoupling of replacement intentions and perceived product quality and fails to predict the increased impact of attributes valued in the interpersonal domain. In contrast, the assumption that anthropomorphic thought grounds object cognition in social cognition provides a parsimonious account of all findings.

In the social realm, people are reluctant to replace close others and our findings suggest that the same is true for anthropomorphized possessions. Numerous variables - from social norms to personal attachment and high regard for persons and objects with which we form a unit relationship (Heider, 1958)-are likely to contribute to this hesitancy. More importantly, in the social realm, information of instrumental relevance, pertaining to the other's capability and performance, must be balanced with other information such as communality and intentions, both of which often matter more than (and do not correlate perfectly with) actual outcomes (Falk, Fehr \& Fischbacher, 2008; Ybarra et al., 2008). Hence, instrumental considerations are often of limited relevance in the decision to maintain or terminate a social relationship. Our observation that replacement intentions are decoupled from perceived car quality suggests that the same applies to anthropomorphized possessions. Conversely, information that bears on the other's sociability and trustworthiness is of high relevance to relationship decisions. Perceptions of the other as "cold" and calculating or "warm" and trustworthy (Asch, 1946) figure prominently in these considerations as a long stream of research in person perception documents (for a recent review see Williams \& Bargh, 2008). Again, our findings suggest that the same qualities figure prominently in decisions about anthropomorphized possessions. Future research may fruitfully explore whether the observed differences are primarily driven by connotations of warmth, coldness, or both. Finally, acting in socially considerate ways is central to many people's identities (Uchronski, 2008) and consumers readily use possessions to affirm important identities and values (Shavitt et al., 2009). If so, possessions may play a more prominent role in identity based motivation (Oyserman, 2009) when they are anthropomorphized than when they are not; this possibility awaits further research.

\section{Implications}

Anthropomorphizing products may have beneficial as well as adverse consequences for both consumers and companies. On the one hand, the increased attachment resulting from 
anthropomorphizing a product (say a car) may lead consumers to invest more in maintaining it. If so, consumers may benefit from an increased life span of their possessions and businesses from the services and products required for proper maintenance. On the other hand, anthropomorphizing a product reduces consumers' willingness to replace it, as seen in the present studies. This may potentially increase consumers' maintenance cost beyond economically defensible levels while reducing producers' sales. To date, we know little about these applied implications, which provide a promising avenue for further research. In contrast, anthropomorphizing brands (rather than products) may be more clearly beneficial from a marketer's perspective: whereas loyalty to a specific object interferes with its replacement, loyalty to the brand encourages replacement of the object with another exemplar from the brand.

Our findings further show that anthropomorphic cues can direct attention away from some features and towards others. This may allow marketers to increase the likelihood that desirable features are attended to, while decreasing the attention paid to undesirable features. But as previous research noted, this strategy may come with consequences that are not always obvious. Anthropomorphic cues may turn an otherwise innocuous air intake grille into a welcoming smile or a threatening scowl or may allow an idiosyncratic collection of objects to become a family (Aggarwal \& McGill, 2007). To the extent that anthropomorphic perceptions elicit corresponding relational expectations, consumers may also respond negatively when the product does not live up to them. For example, Aggarwal (2004) found that people dislike products that imply a specific kind of interpersonal relationship style (e.g. a communal or exchange orientation) once they realize that the product does not live up to the norms associated with it. Similarly, anthropomorphic primes may direct consumers' attention away from the physical quality of a product and towards other, less instrumental features, as observed in Study 2. This could hurt products of superior technical quality and benefit competitors with more appealing "interpersonal" features. In addition to changing perceptions of the product itself, shifting attention to relational features of the product may also change the effect of owning a product on a consumer's sense of self (Belk, 1988; Kirmani, 2009). For example, to the extent that communality is an important part of people's selfconcept, investing in the maintenance of anthropomorphized products may make them feel better about themselves.

Finally, the observation that anthropomorphic thought is easily elicited by asking for trait ratings raises a potentially important methodological concern for market research surveys. Stimulated by research into brand personality (Aaker, 1997), many applied market research surveys assess consumers' perceptions of a brand by asking for ratings that usually include a mix of anthropomorphic (e.g. "honest") and non-anthropomorphic (e.g. "rugged") traits. Our findings suggest that the anthropomorphic traits may foster anthropomorphized perceptions of the brand with downstream effects on intentions. If so, collecting ratings of agentic traits may introduce a previously unobserved source of systematic context effects in market research (Weaver \& Schwarz, 2008), potentially undermining the predictive value of respondents' answers for consumers who were not first induced to think in anthropomorphic terms. Future research may fruitfully address this possibility.

\section{Acknowledgments}

The reported research was supported by a Graduate Fellowship from the Social Sciences and Humanities Research Council of Canada to the first author. We thank Hans IJzerman, Michal Parzuchowski and three anonymous reviewers for their comments and suggestions.

\section{References}

Aaker, J., \& Akutsu, T. (2009). Why do people give? The role of identity in giving. Journal of Consumer Psychology, 19, 267-270.

Aaker, J., Fournier, S., \& Brasel, S. A. (2004). When good brands do bad. Journal of Consumer Research, 31, 1-16.

Aaker, J. L. (1997). Dimensions of brand personality. Journal of Market Research, 34, 346-356.

Aggarwal, P. (2004). The effects of brand relationship norms on consumer attitudes and behavior. Journal of Consumer Research, 31, 87-101.

Aggarwal, P., \& McGill, A. L. (2007). Is that car smiling at me? schema congruity as a basis for evaluating anthropomorphized products. Journal of Consumer Research, 34, 468-479.

Asch, S. E. (1946). Forming impressions of personality. Journal of Abnormal and Social Psychology, 41, 258-290.

Ball, A. D., \& Tasaki, L. H. (1992). The role and measurement of attachment in consumer behavior. Journal of Consumer Psychology, 2, 155-172.

Belk, R. W. (1988). Possessions and the extended self. Journal of Consumer Research, 15, 139-168.

Bering, J. M. (2006). The folk psychology of souls. Behavioral and Brain Sciences, 29, 453-462.

Berry, D. S., \& Springer, K. (1993). Structure, motion, and preschoolers' perceptions of social causality. Ecological Psychology, 5, 273-283.

Bowlby, J. (1980). Attachment and loss, Vol. III,New York: Basic Books, Inc.

Branscombe, N. R., Wann, D. L., Noel, J. G., \& Coleman, J. (1993). In-group or out-group extremity: Importance of threatened social identity. Personality and Social Psychology Bulletin, 19, 381-388.

Cohen, J., Cohen, P., West, S. G., \& Aiken, L. S. (2003). Applied Multiple Regression/Correlation Analysis for the Behavioral Sciences, 3rd Edition. London: Lawrence Erlbaum Associates, Inc.

Cosmides, L. (1989). The logic of social exchange: Has natural selection shaped how humans reason? Studies with the Wason Selection Task. Cognition, 31, $187-276$.

Disch, T. (1987). The brave little toaster. New York: Doubleday.

DuPont, (2006). DuPont reports global color popularity ratings for vehicles. In DuPont Press Releases. Retrieved September 14, 2009, from http:// vocuspr.vocus.com/VocusPR30/Newsroom/Query.aspx?SiteName= DupontNew\&Entity=PRAsset\&SF_PRAsset_PRAssetID_EQ=111443\&XSL= PressRelease \&Cache $=$ False

Epley, N., Akalis, S., Waytz, A., \& Cacioppo, J. T. (2008). Creating social connection through inferential reproduction: Loneliness and perceived agency in gadgets, gods, and greyhounds. Psychological Science, 19, $114-120$.

Epley, N., Waytz, A., Akalis, S., \& Cacioppo, J. T. (2008). When we need a human: Motivational determinants of anthropomorphism. Social Cognition, 26, 143-155.

Epley, N., Waytz, A., \& Cacioppo, J. T. (2007). On seeing human: A threefactor theory of anthropomorphism. Psychological Review, 114, 864-886.

Falk, A, Fehr, E., \& Fischbacher, U. (2008). Testing theories of fairnessIntentions matter. Games and Economic Behavior, 62, 287-303.

Guthrie, S. (1993). Faces in the clouds: A new theory of religion. New York: Oxford. 
Haley, K. J., \& Fessler, D. (2005). Nobody's watching? Subtle cues affect generosity in an anonymous economic game.. Evolution \& Human Behavior, 26, 245-256.

Heider, F. (1958). The psychology of interpersonal relations. Hoboken, NJ: John Wiley \& Sons, Inc.

Heider, F., \& Simmel, M. (1944). An experimental study of apparent behavior. American Journal of Psychology, 57, 243-249.

Higgins, E. T. (1996). Knowledge activation: Accessibility, applicability, and salience. In E. T. Higgins, \& A. W. Kruglanski (Eds.), Social psychology: Handbook of basic principles (pp. 133-168). New York: Guilford Press.

Ijzerman, H., \& Semin, G. (2009). The thermometer of social relationships: Mapping social proximity on temperature. Psychological Science, 20, 1214-1220.

Jipson, J. L., \& Gelman, S. A. (2007). Robots and rodents: Children's inferences about living and nonliving kinds. Child Development, 78, 1675-1688.

Jones, D. C., \& Vaughan, K. (1990). Close friendships among senior adults. Psychology \& Aging, 5, 451-457.

Jones, S. S., Smith, L. B., \& Landau, B. (1991). Object properties and knowledge in early lexical learning. Child Development, 62, 499-516.

Kirmani, A. (2009). The self and the brand. Journal of Consumer Psychology, 19, 271-275.

Kubrick, S. (1968). 2001: A space odyssey [Motion picture].MGM: United States (Producer and Writer).

Leach, C. W., Ellemers, N., \& Barreta, M. (2007). Group virtue: The importance of morality (vs. competence and sociability) in the positive evaluation of ingroups. Journal of Personality and Social Psychology, 93, 234-249.

Levine, J. M., \& Moreland, R. L. (2002). Group reactions to loyalty and disloyalty. In S. R. Thye, \& E. J. Lawler (Eds.), Group cohesion, trust and solidarity (pp. 203-228). US: Elsevier Science/JAI Press.

Levine, M. (2009, March 9). Share my ride. : New York Times Magazine.

Mitchell, J. P., Heatherton, T. F., \& Macrae, C. N. (2002). Distinct neural systems subserve person and object knowledge.Proceedings of the National Academy of Sciences, 99, 15238-15243 (November).

Oyserman, D. (2009). Identity-based motivation: Implications for actionreadiness, procedural-readiness, and consumer behavior. Journal of Consumer Psychology, 19, 250-260.

Rosenthal, R., Rosnow, R. L., \& Rubin, D. B. (2000). Contrasts and effect sizes in behavioral research. New York: Cambridge.

Schultz, S. E., Kleine, R. E., \& Kernan, J. B. (1989). These are a few of my favorite things': toward an explication of attachment as a consumer behavior construct. Advances in consumer research (pp. 359-366)., 16, ed. Thomas Srull, Provo, UT: Association for Consumer Research.

Schwarz, N. (1996). Cognition and communication: Judgmental biases, research methods, and the logic of conversation. New Jersey: Lawrence Erlbaum Associates.

Shavitt, S., Torelli, C. J., \& Wong, J. (2009). Identity based motivation: Constraints and opportunities. Journal of Consumer Psychology, 19, 261-266.

Simmons, R., Marine, S. K., \& Simmons, R. L. (1977). Gift of life: The effect of organ transplantation on individual, family, and societal dynamics. New Brunswick, NJ: Transaction Publishers.

Thomson, M., MacInnis, D. J., \& Park, C. W. (2005). The ties that bind Measuring the strength of consumers' emotional attachment to brands. Journal of Consumer Psychology, 15, 77-91.

Uchronski, M. (2008). Agency and communion in spontaneous self-descriptions: Occurrence and situational malleability. European Journal of Social Psychology, 38, 1093-1102.

Wallendorf, M., \& Arnould, E. J. (1988). "My favorite things": A cross-cultural inquiry into object attachment, possessiveness, and social linkage. Journal of Consumer Research, 14, 531-547.

Wang, L. C., Baker, J., Wagner, J. A., \& Wakefield, K. (2007). Can a retail website be social? Journal of Marketing, 71, 143-157.

Weaver, K., \& Schwarz, N. (2008). Self-reports in consumer research. In C. Haugtvedt, P. Herr, \& F. Kardes (Eds.), Handbook of consumer psychology (pp. 1081-1102). Mahwah, NJ: Erlbaum.

Williams, L. E., \& Bargh, J. A. (2008). Experiencing physical warmth promotes interpersonal warmth. Science, 322, 606-607.

Wojciszke, B., Bazinska, R., \& Jaworski, M. (1998). On the dominance of moral categories in impression formation. Personality and Social Psychology Bulletin, 24, 1245-1257.

Woodward, A. (1999). Infants' ability to distinguish between purposeful and nonpurposeful behaviors. Infant Behavior and Development, 22, 145-160.

Ybarra, O., Chan, E., Park, H., Burnstein, E., Monin, B., \& Stanik, C. (2008) Life's recurring challenges and the fundamental dimensions: An integration and its implications for cultural differences and similarities. European Journal of Social Psychology, 38, 1083-1092.

Yoon, C., Gutchess, A. H., Feinberg, F., \& Polk, T. A. (2006). A functional magnetic resonance imaging study of neural dissociations between brand and person judgments. Journal of Consumer Research, 33, 31-40.

Zentes, J., Morschett, D., \& Schramm-Klein, H. (2008). Brand personality of retailers: An analysis of its applicability and its effect on store loyalty. The International Review of Retail, Distribution and Consumer Research, 18, 167-184. 